\title{
Urinary Pteridine Levels during Proliferation of Malignant and Normal Cells
}

\author{
Sunil TREHAN* and John M. NORONHA** \\ Radiation Biology and Biochemistry Division, \\ Bhabha Atomic Research Centre, \\ Bombay 400 085, India
}

(Received February 16, 1995)

\begin{abstract}
Summary A rapid method was described earlier for estimation of total urinary pteridines, a method found suitable for monitoring cancer patients under therapy (Trehan and Noronha [1993] J. Clin. Biochem. Nutr., 14, 195-203). This method was employed in the present study for monitoring development of Yoshida ascites tumor and regeneration of liver in partially hepatectomized rats. During tumor development the total urinary pteridines to creatinine ratio was found to increase progressively by more than five fold. The progressive increase in urinary pteridine levels correlated well with the tumor development. However, when partially hepatectomized rats with rapidly regenerating normal liver cells were monitored over a 13-day post-hepatectomy period, almost normal excretory levels of pteridines were found throughout this regeneration period. This clearly brings out that though both the systems investigated involved proliferating cells, the increased urinary pteridine excretion was associated solely with malignant cell growth and not with proliferating normal tissue.
\end{abstract}

Key Words: pteridines, cell proliferation, tumor development, liver regeneration

Pteridines, including neopterin, have attracted a great deal of interest in recent years due to their clinical significance [1-3]. A rapid assay for urinary pteridines was described earlier, which assay was found to be useful for monitoring cancer patients during therapy and as a tool for detection and staging of cancer [4]. We now report here the pattern of total urinary pteridine excretion investigated in two commonly employed laboratory model systems with actively proliferating cells.

*To whom correspondence should be addressed.

${ }^{* *}$ Deceased on January 25, 1995. 
The systems investigated were rats with proliferating Yoshida ascites tumor cells and partially hepatectomized rats with rapidly regenerating liver cells.

\section{MATERIALS AND METHODS}

Experimental animals and urine sampling. Male Wistar rats weighing $150 \pm 5 \mathrm{~g}$ (around 6 weeks of age) and maintained on a normal laboratory diet with water provided ad libitum were employed in this study. For studies involving tumor growth, some animals were transplanted intra-peritoneally with $10^{6}$ cells of the Yoshida ascites sarcoma tumor AH 130. And for those involving liver regeneration, another group of animals were hepatectomized, with around $70 \%$ of their liver consisting of left and median lobes surgically excised under anesthesia (ether) under sterile conditions. Normal animals as well as sham-operated animals were used as controls.

All these animals were kept in separate metabolic cages on $20 \%$ glucose for the first $24 \mathrm{~h}$, followed by normal food and water. Overnight urine samples were collected into tubes containing $200 \mu 1$ of toluene. The samples were drawn for analysis every morning at a fixed time, and the animals were transferred to fresh metabolic cages for the next day's sampling. The daily urine samples were collected from animals with ascites tumor for 7 days, by which time the animals succumbed due to the growing tumor cell load. The samples for the partially hepatectomized animals were collected for a 13-day period after hepatectomy.

Chemicals. All chemicals and solvents employed were of analytical grade. The pteridine standards were purchased from Dr. B. Schircks Laboratories, Jona, Switzerland.

Estimation of total urinary pteridines by fluorometry. Urinary pteridines were determined by fluorometric methods as described earlier [4]. In brief, $100 \mu 1$ of a fresh urine sample was oxidized with iodine under alkaline conditions by the addition of $10 \mu 1$ each of $2 \mathrm{M} \mathrm{NaOH}$ and $2 \%$ iodine solution in $4 \%$ potassium iodide. After an incubation for $10 \mathrm{~min}$ at room temperature the oxidation was terminated by the addition of $10 \mu 1$ of $2 \%$ ascorbic acid, and the mixture was then centrifuged at $2,000 \times g$ for $10 \mathrm{~min}$. The clarified supernatant was diluted with water to $5 \mathrm{ml}$ before reading its fluorescence against quinine sulphate solution as reference standard by the use of a Model F-3010 fluorescence spectrophotometer (Hitachi, Ltd., Tokyo). A concentration of $1 \mu \mathrm{g} / \mathrm{ml}$ quinine sulphate in $0.1 \mathrm{~N}$ $\mathrm{H}_{2} \mathrm{SO}_{4}$ was found to emit fluorescence at $450 \mathrm{~nm}$ (with excitation at $360 \mathrm{~nm}$ ) equivalent to that for a $135.7 \mu \mathrm{g} / \mathrm{ml}$ solution of pteridine mixture composed of neopterin (45\%), biopterin (45\%), and pterin-6-carboxylic acid (10\%). A calibration plot of the quinine sulphate solution against a mixture of the above standard pteridines was found to exhibit a linear correlation.

Creatinine estimation. Creatinine estimation involving development of color with alkaline picric acid employing Jaffe's principle and as described by Oser [5] was suitably modified as explained earlier [4]. To a $0.5 \mathrm{ml}$ aliquot of the above 
oxidized urine sample or the standard solution $(2 \mathrm{mg} \%$ creatinine in $0.1 \mathrm{~N} \mathrm{HCl})$ or the blank (water) was added $0.5 \mathrm{ml}$ of $1.2 \mathrm{~N}$ trichloroacetic acid, and the mixture was then centrifuged at $4,000 \times g$ for $10 \mathrm{~min}$. The supernatant was added to $1 \mathrm{ml}$ of a $1: 1$ mixture of $1.6 \mathrm{~N} \mathrm{NaOH}$ and $35 \mathrm{~mm}$ picric acid and incubated for $20 \mathrm{~min}$ at room temperature. The color developed was read at $520 \mathrm{~nm}$ by use of a Model U-2000 spectrophotometer (Hitachi, Ltd., Tokyo).

\section{RESULTS AND DISCUSSION}

\section{Monitoring Yoshida ascites tumor in rats}

Total urinary pteridines were estimated daily for a group of rats at progressive stages of tumor development after transplantation of Yoshida ascites tumor cells. Urinary creatinine levels were estimated simultaneously during progression of the tumor. In order to eliminate errors linked with variations in the amount of fluid intake by the individual animals at various stages of tumor development, we expressed total pteridine levels as ratio to the urinary creatinine levels. The results were compared with the urinary pteridine/creatinine ratios for the sham-injected controls (normal saline).

Urinary pteridines/creatinine excretory levels for rats transplanted with the Yoshida ascites tumor were higher than those of the controls. The data in Table 1 present the daily excretory levels of three tumor-bearing animals maintained in separate metabolic cages. The normal control animals were observed to excrete $25.33 \pm 8.37 \mu \mathrm{g}$ pteridines $/ \mathrm{mg}$ creatinine $(n=30)$, with a range from 15.2 to 33.6 $\mu \mathrm{g} / \mathrm{mg}$ creatinine. On the fifth day after transplantation of the tumor the urinary pteridine levels were observed to reach a peak of $138.02 \pm 25.5 \mu \mathrm{g} / \mathrm{mg}$ creatinine (range 106.4 to $168.8 \mu \mathrm{g} / \mathrm{mg}$ creatinine). These levels were nearly six fold higher as compared with those of the controls. One way analysis of variance was carried out on a computer using the NCSS (Number Cruncher Statistical System) package. Employing Scheffe's test for multiple comparisons, a significant difference was found between the 5 -day tumor animals and the controls $(p<0.01)$. On the seventh

Table 1. Urinary pteridines/creatinine ratios on various days after Yoshida ascites tumor transplantation in Wistar rats.

\begin{tabular}{cccccc}
\hline \multirow{2}{*}{ Day } & \multicolumn{4}{c}{ Urinary pteridines/creatinine $(\mu \mathrm{g} / \mathrm{mg})$} & \multirow{2}{*}{$\begin{array}{c}\text { Level of } \\
\text { significance }\end{array}$} \\
\cline { 2 - 5 } & Exp. 1 & Exp. 2 & Exp. 3 & Mean SD & \\
\hline 0 & 15.2 & 33.6 & 19.0 & $22.57 \pm 7.94$ & ns \\
1 & 19.6 & 48.5 & 21.4 & $29.82 \pm 13.20$ & ns \\
2 & 39.4 & 60.0 & 18.6 & $39.32 \pm 16.91$ & ns \\
3 & 46.7 & 89.3 & 31.4 & $55.79 \pm 24.49$ & ns \\
4 & 89.4 & 104.4 & 67.9 & $87.25 \pm 15.00$ & $p<0.01$ \\
5 & 106.4 & 138.9 & 168.8 & $138.02 \pm 25.50$ & $p<0.05$ \\
6 & 95.6 & 167.1 & 123.3 & $128.68 \pm 29.47$ & ns \\
7 & 74.5 & 130.0 & 129.2 & $111.26 \pm 25.96$ & \\
\hline
\end{tabular}

ns, non-significant change with respect to control (Day 0) animals. 
day after tumor inoculation the animals were observed to be highly sluggish, with a very low food and water intake. Finally, due to the increased load of proliferating tumor cells, the animals succumbed to death at about this time ( 7 days). Before death the mean total pteridine level was observed to be $111.26 \pm 25.96 \mu \mathrm{g} / \mathrm{mg}$ creatinine, marginally lower than the peak level on the fifth day.

The increase in urinary pteridines correlates well with the progression of Yoshida ascites tumor growth in Wistar rats. These findings are in good agreement with the previously described results on the growth of Ehrlich ascites tumor cells in mice, where the urinary levels of the pteridine derivative 7,8-dihydro-6hydroxylumazine were found to be directly proportional to the progress of tumor growth [6].

\section{Urinary pteridines during liver regeneration}

Regenerating liver after partial hepatectomy is known to exhibit a rapid cell proliferation [7]. Since urinary pteridines/creatinine ratios were found to increase during tumor cell proliferation, we were next interested in conducting another set of experiments to investigate their excretory pattern during rapid regeneration of normal liver cells after partial hepatectomy in rats.

After surgically removing nearly $70 \%$ of the liver, we monitored the urinary pteridines excreted by these rats for a 13-day post hepatectomy period and compared the results with those on sham-operated as well as normal animals.

During this 13-day period of active liver regeneration, no statistically significant variations in the urinary pteridines or creatinine excretion were observed. While the control (Day 0) animals excreted $20.44 \pm 6.691 \mu \mathrm{g}$ pteridines $/ \mathrm{mg}$ creatinine (Table 2), the sham-operated animals were found to excrete around

Table 2. Failure to monitor progress of liver regeneration in partially hepatectomized Wistar rats in terms of daily urinary total pteridines/creatinine ratio.

\begin{tabular}{|c|c|c|c|c|c|c|c|}
\hline \multirow{2}{*}{ Day } & \multicolumn{6}{|c|}{ Pteridines/creatinine levels $(\mu \mathrm{g} / \mathrm{mg})$} & \multirow{2}{*}{$\begin{array}{c}\text { Level of } \\
\text { significance }\end{array}$} \\
\hline & Exp. 1 & Exp. 2 & Exp. 3 & Exp. 4 & Exp. 5 & Mean SD & \\
\hline 0 & 15.2 & 33.6 & 17.0 & 19.0 & 17.4 & $20.44 \pm 6.69$ & \\
\hline 1 & 26.9 & 76.5 & 15.6 & 14.3 & 46.4 & $35.94 \pm 23.32$ & ns \\
\hline 2 & 16.3 & 13.1 & 13.2 & 10.0 & 26.0 & $15.71 \pm 5.52$ & ns \\
\hline 3 & 20.5 & 12.7 & 11.6 & 21.2 & 26.1 & $18.43 \pm 5.49$ & ns \\
\hline 4 & 20.8 & 45.2 & 9.9 & 17.1 & 28.5 & $24.30 \pm 12.04$ & ns \\
\hline 5 & 21.1 & 15.3 & 30.3 & 12.6 & 28.9 & $21.65 \pm 7.07$ & ns \\
\hline 6 & 27.5 & 15.7 & 15.2 & 13.2 & 27.3 & $19.78 \pm 6.27$ & ns \\
\hline 7 & 24.8 & 17.8 & 38.0 & 14.0 & 28.3 & $24.57 \pm 8.39$ & ns \\
\hline 8 & 29.4 & 13.9 & 25.0 & 12.6 & 26.4 & $21.45 \pm 6.86$ & ns \\
\hline 9 & 19.8 & 15.5 & 23.6 & 15.0 & 25.1 & $19.80 \pm 4.11$ & $\mathrm{~ns}$ \\
\hline 10 & 15.3 & 9.6 & 13.0 & 11.2 & 25.4 & $14.91 \pm 5.58$ & ns \\
\hline 11 & 22.1 & 15.0 & 7.7 & 14.3 & 24.7 & $16.74 \pm 6.05$ & ns \\
\hline 12 & 14.3 & 11.3 & 12.6 & 22.7 & 23.1 & $16.80 \pm 5.07$ & ns \\
\hline 13 & 17.5 & 12.7 & 9.7 & 11.8 & 22.9 & $14.92 \pm 4.74$ & ns \\
\hline
\end{tabular}

ns, non-significant change with respect to control (Day 0) animals. 
$18.25 \pm 0.34 \mu \mathrm{g} / \mathrm{mg}$ creatinine. The partially hepatectomized animals excreted generally between 15 to $35 \mu \mathrm{g} / \mathrm{mg}$ creatinine (with an overall mean of $20.39 \mu \mathrm{g}$ / $\mathrm{mg}$ creatinine), which was well within the normal range. Hence the pteridine excretory levels did not differ significantly between the partially hepatectomized animals and the controls.

These results have important metabolic implications, in that pteridines are seen to be excreted in the urine in a proliferating tumor cell system (Yoshida ascites) but not during proliferation of normal healthy cells (liver regeneration). The exact significance of increased pteridine excretion during tumor cell proliferation is still not understood; however, it has been shown that pteridines are released by macrophages when stimulated by interferon- $\gamma$ released from activated T-lymphocytes [8]. In the macrophages GTP-cyclohydrolase is activated, and it converts large quantities of GTP to the first pteridine derivative, 7,8-dihydro-neopterintriphosphate.

\section{REFERENCES}

1. Müller, M.M., Curtius, H.C., Herold, M., and Huber, C.H. (1991): Neopterin in clinical practice. Clin. Chim. Acta, 201, 1-16.

2. Fuchs, D., Kramer, A., Reibnegger, G., Werner, E.R., Dierich, M.P., Geodert, J.J., and Wachter, H. (1991): Neopterin and $\beta_{2}$-microglobulin as prognostic indices in human immunodeficiency virus type 1 infection. Infection, 19, S98-S102.

3. Noronha, J.M., and Trehan, S. (1990): Urinary excretion of total pteridines in cancer, in Chemistry and Biology of Pteridines, ed. by Curtius, H.-Ch., Ghisla, S., and Blau, N., Walter de Gruyter, Berlin/New York, pp. 515-518.

4. Trehan, S., and Noronha, J.M. (1993): A rapid assay for urinary pteridine levels for monitoring cancer. J. Clin. Biochem. Nutr., 14, 195-203.

5. Oser, B.L. (1965): Urine: Quantitative analysis, in Hawk's Physiological Chemistry, ed. by Oser, B.L., McGraw-Hill Book Company Inc., New York, pp. 1233-1238.

6. Lutz, H., Fuchs, D., Fuith, L., Hausen, A., Reibnegger, G., and Wachter, H. (1984): Measurement of urinary 7,8-dihydro-6-hydroxylumazine in healthy and in Ehrlich ascites tumor bearing mice. Hoppe-Seyler's Z. Physiol. Chem., 365, 895-900.

7. Bresnick, E. (1971): Regenerating liver: An experimental model for the study of growth, in Methods in Cancer Research, ed. by Busch, H., Academic Press, New York/London, pp. 347-397.

8. Fuchs, D., Weiss, G., and Wachter, H. (1993): Neopterin, biochemistry and clinical use as a marker for cellular immune reactions. Int. Arch. Allergy Immunol., 101, 1-6. 